\title{
¿Migración neohispánica? El impacto de la crisis económica en la emigración española ${ }^{1}$
}

\author{
¿Neo-Hispanic Migration? The impact of the economic recession \\ on Spanish emigration
}

\author{
Andreu Domingo i Valls \\ Universidad Autónoma de Barcelona \\ Albert Sabater Coll \\ Investigador senior en la School of Geography and Geosciences de la University of St \\ Andrews. \\ Enrique Ortega Rivera \\ Universidad Autónoma de Barcelona \\ adomingo@ced.uab.es (ESPAÑA)
}

Recibido: 29.06 .2013

Aceptado: 25.05.2014

\section{RESUMEN}

Uno de los principales efectos de la crisis es el fenómeno reemergente de la emigración española, sobre todo a partir del año 2011. En este artículo se examina dicha emigración desde 2008 hasta los últimos datos publicados de 2012, tomando en consideración la población nacida en España y aquella de procedencia extranjera nacionalizada española, utilizando la Estadística de Variaciones Residenciales (EVR), del INE. Se contextualizan esos flujos por nacionalidad y lugar de nacimiento en la evolución de la crisis económica, y en el discurso que se ha enunciado ante la incertidumbre abierta tanto por la escasa fiabilidad de los datos recogidos como por las consecuencias del ajuste económico. Se identifican los principales países receptores y provincias emisoras y, finalmente, dos características demográficas básicas (edad y sexo), permitiéndonos describir y discriminar una parte importante de la compleja emigración y/o movilidad actual que tiene su punto de partida desde España, y que hemos calificado de "neohispánica".

${ }^{1}$ Artículo realizado en el marco de la investigación financiada por el Plan Nacional de I+D+I 2011 ¿De la complementariedad a la exclusión? Análisis sociodemográfico del impacto de la crisis económica en la población inmigrada (Ref. CSO2011/24501). Este texto además forma parte de la tesis doctoral de Enrique Ortega "La emigración española hacia Europa en el contexto de crisis económica: análisis sociodemográfico" dirigida por el Doctor Andreu Domingo e inscrita en el Departament de Geografía de la Universitat Autònoma de Barcelona. 


\title{
PALABRAS CLAVE
}

Emigración, España, Demografía, Crisis Económica.

\begin{abstract}
One of the main effects of the current crisis is re-emerging phenomenon of Spanish emigration, especially since year 2011. This paper examines the growth of emigration from 2008 to 2012, using disaggregated data by origin, age, sex as well as geography detail at provincial level from the Residential Variation Statistics. The analyses distinguish between native-born and foreign-born with and without the Spanish nationality, and highlight recent trends as a result of the prolonged economic recession and its impact on international migration. Although the use of this dataset which contains time series data enable us to provide a relevant picture of the main demographic profiles of current emigration, the data too have uncertainties embedded within, not least because many of the new emigrants have not registered yet at the destination country. However, the data examination allows us to identify different patterns, including the main recipient countries as well as the provincial geography of emigration, and the main demographic profiles of emigrants. The results shed some light of what could be considered as Neo-Hispanic migration given the apparent diversity of outflows.
\end{abstract}

\section{KEY WORDS}

Emigration, Spain, Demography, Economic Crisis.

\section{INTRODUCCIÓN: EL PRONÓSTICO Y EL ETERNO RETORNO}

Uno de los efectos más impactantes de la crisis económica sobre la dinámica migratoria desde su inicio a mitades del 2008, ha sido no sólo el esperable descenso de los flujos inmigratorios y el progresivo aumento de las salidas de extranjeros, sino la incipiente emigración de españoles. Desde el primer año en el que se hace patente la crisis hasta 2012 (último con datos disponibles), se han registrado en España 153.734 bajas de españoles nacidos en España y 62.602 bajas correspondientes a nacionalizados españoles, representando éstas últimas el 28,9\% del total de bajas de españoles. La evolución en la salida de españoles nacidos en España ha sido notablemente creciente, pasando de las casi 26 mil salidas en 2008 a unas 38 mil en 2011, es decir un aumento del $31,7 \%$, produciéndose la mayor parte de este salto en 2011 (con un aumento neto de 11.215 bajas más), para estabilizarse en 2012 con 37.675, experimentando incluso un ligero descenso de 253 bajas. A este movimiento debemos añadir la salida de casi unos 19 mil residentes nacionalizados españoles, bajas que desde 2008 no han hecho más que incrementarse (un 70\%). 
Con un paro creciente, que alcanzaba al $27 \%$ de la población entre 25 y 35 años en el segundo trimestre de 2012, y un futuro cada vez más incierto, la emigración ha sido la única solución que se les ha brindado a los jóvenes españoles, a los que ya se ha bautizado como "generación perdida". Desde la firma de los acuerdos de Schengen en 1996, como aparece en su anexo con una propuesta de política migratoria que apuntaba en esa dirección, la promoción de los movimientos circulares para la migración extracomunitaria de baja cualificación, y el reclutamiento de migración altamente cualificada de países terceros, han constituido la brújula de la política migratoria de la UE. En este contexto, la emigración de españoles, ha eclipsado por su novedad al fenómeno de la emigración relacionada con la reciente inmigración internacional (emigración de extranjeros, de extranjeros nacionalizados españoles y de sus descendientes o cónyuges, nacidos en España con nacionalidad española). A pesar de que esta emigración sea muy superior en términos de volumen, presente un gran potencial de crecimiento, y signifique también una pérdida de capital humano.

Hay un consenso en aceptar que la emigración o movilidad de jóvenes españoles altamente cualificados puede ser un fenómeno emergente (Domingo y Recaño, 2010), compartido con otros países comunitarios sometidos a un ajuste estructural (Grecia, Portugal, o Irlanda, por ejemplo). No obstante, otros países no sometidos a dicho ajuste (Alemania el principal representante) no solo se ven afectados por una mayor circularidad de sus trabajadores cualificados (Kahanec and Zimmermann, 2011), también por el poder de atracción de otros países (conocidos como emergentes) que han sido capaces de revertir los viejos patrones de migración internacional (OECD, 2009a), representando una rivalidad por las destinaciones tradicionales (el Reino Unido, Estados Unidos, Canadá y Australia). En este contexto, las recientes medidas adoptadas por la UE, como la Tarjeta Azul UE (Directiva 2009/50/CE) ${ }^{2}$, muestran cierto compromiso ante la competencia de otras regiones del mundo, aunque la progresiva pérdida de jurisdicción en materia de inmigración ha sido ampliamente criticada por países como los Países Bajos, Alemania y Austria, y simplemente no aceptada por países como el Reino Unido, Irlanda y Dinamarca (ILO, 2010). Ante esta situación, la carrera para captar migrantes cualificados ha sido una tónica acelerada desde el inicio de la recesión económica en 2008 (MPI, 2008), siendo la movilidad intraeuropea una parte creciente y nada desdeñable.

Aunque los datos con que contamos no nos permiten dar respuesta a muchos de los interrogantes que se plantean como, por ejemplo, la motivación principal (estudio o trabajo) o el nivel educativo, sí nos permiten entrever una nueva realidad migratoria, la de la emigración de españoles, convertida a la vez en alegoría demográfica y primer resultado palpable del paso de la crisis económica al ajuste estructural en España. Aún así, parece claro que la nueva

${ }^{2}$ La Tarjeta azul define las condiciones y procedimientos de admisión de los nacionales extracomunitarios altamente cualificados, con la finalidad de facilitar y simplificar los trámites de admisión, y mejorar el estatuto de los que ya se encuentran en territorio comunitario. 
emigración española no puede equipararse a la emigración secular anterior al nuevo milenio, salvo por tener la penuria económica como motor. Ni los perfiles socio demográficos de sus protagonistas, ni los territorios a los que afectan, ni el sistema demográfico en el que se insieren es el mismo. En la emigración de antaño los hombres eran los pioneros y la baja cualificación mayoritaria. En la actual, la igualdad entre hombres y mujeres en los flujos, junto con el peso de los estudios superiores concordante con la mejora del nivel de instrucción en las jóvenes generaciones españolas, constituyen las características más remarcables. En términos de dinámica y estructura demográficas, la joven España emigratoria de siglos pasados poco se parece a la envejecida España caracterizada por un sistema complejo de reproducción, con presencia simultánea de inmigración y emigración.

La conjunción de la deficiente cobertura estadística, que trataremos acto seguido, y la alarma social que ha provocado un posible horizonte de reemigración, han añadido un interés especial al estudio de este fenómeno, que ilustra la construcción de un discurso determinado sobre la población y sus repercusiones en las acciones de los individuos. Nos referimos a la polémica que ha suscitado la interpretación de esos escasos y deficientes datos, y cómo la misma puede estar cambiando el fenómeno. En un trabajo anterior hablábamos de profecía autocumplida (Domingo y Sabater, 2013), ya que nuestra hipótesis es que la magnificación de la emigración española, por razones políticas y mediáticas puede estar influyendo en su crecimiento real, en un proceso de problematización descrito hace una década por el sociólogo Rémi Lenoir (1993), en la que se podrían distinguir una serie de factores: en primer lugar, las transformaciones que afectan a la vida cotidiana de los individuos -aquí la crisis económica- y cuyos efectos difieren según los grupos sociales. Estas nuevas condiciones objetivas se convierten en un problema social mediante un proceso de formulación pública a través de su evocación -aparición de la emigración española en los medios de comunicación-, imposición -en los debates públicos-, legitimación -la consagración o reconocimiento por parte de las instancias oficiales-, y, finalmente, institucionalización -con la firma de acuerdos de reclutamiento y gestión de contrataciones con otros países-.

No es éste un hecho baladí. Mientras los medios de comunicación difunden machaconamente la emigración de jóvenes españoles como un drama masivo acorde con la narrativa de la "generación perdida" como sacrificio necesario en aras del mercado, y los políticos se aprestan a la escenificación de esa "nueva urgencia" redentora, al proclamar que se van a tomar medidas de acompañamiento a esos flujos (dando por supuesto que nada se puede hacer efectivamente para retener a esa población, ni siquiera para luchar contra un desempleo generado por las medidas de austeridad), la mayoría de profesionales que se han acercado a los datos, tienden a desmentir esa agitación y a extraer lecciones que van en una dirección opuesta (Garrido, 2013; González-Ferrer, 2013b; Domingo y Sabater, 2013; Cabré y Domingo, 2014). En el centro de ese divorcio entre los medios de comunicación (si se quiere la opinión pública), los políticos, y los expertos, se sitúa ni más ni menos que la discusión sobre la ca- 
pacidad de las ciencias sociales, aquí la demografía, de interpretar la realidad en el pronóstico y con él de cambiar el presente.

El objetivo de este trabajo es doble: en primer lugar, analizar la emigración española hacia el exterior en el contexto actual de crisis económica, tomando en consideración la población nacida en España y aquella de procedencia extranjera nacionalizada española; $y$, en segundo, mostrar las limitaciones de las fuentes españolas disponibles.

\section{DATOS Y METODOLOGÍA}

Para hacer frente a nuestras preguntas de investigación principal -¿Quiénes están marchando? ¿De dónde marchan? ¿Y hacia dónde van?- en este trabajo se lleva a cabo un examen de la Estadística de Variaciones Residenciales (EVR).

$\mathrm{Si}$ bien el sistema estadístico español tiene razones sobradas para enorgullecerse de su eficiencia en el registro de la inmigración internacional e interna respecto a otros países, gracias a las Estadística de Variaciones Residenciales (EVR), elaboradas por el INE a través de las altas padronales (Poulain et al., 2006), no puede decirse lo mismo de las bajas. Como consecuencia de ello, en comparación con la inmigración, la emigración tanto de nacionales como de extranjeros se caracteriza por su borrosidad estadística, siendo el cómputo de las bajas aún deficiente. Para la población española, dicha deficiencia se traduce muy probablemente en una subestimación, lo que en las circunstancias actuales también debe imputarse tanto a la propia coyuntura migratoria (y con ella al despliegue legislativo subsiguiente), como al interés que para las personas e instituciones implicadas comporta la correcta inscripción de los registros consulares.

Con anterioridad a la crisis, ya se alertó de los problemas que acarreaba un deficiente control de las bajas cuando correspondían a salidas fuera de España (De Castro, 2004; Garrido, 2004). Municipios reacios a perder población, migrantes que por diversos motivos querían mantener su inscripción padronal pese a abandonar el país, y un sistema de control exclusivamente municipal, se conjugaban para dificultar extraordinariamente el apropiado registro de las salidas. Pese a los esfuerzos realizados para estimar el subregistro (Gil, 2010), y las medidas adoptadas por el INE para corregirlo, la deficiente cobertura no ha hecho nada más que aumentar la incertidumbre sobre lo que realmente estaba sucediendo. Las deficiencias del registro de las bajas tiene el mismo origen que en su momento lo tuvo el de las altas: por un lado afecta tanto a españoles como a extranjeros (Sabater y Ajenjo, 2005), por el otro, fundamentalmente se debe a que la inscripción de las bajas no reporta ningún beneficio para los individuos, mientras que el de las altas es generadora de derechos -acceso a la sanidad pública, a la escolarización y requisito para la regularización-. Incluso al contrario, tanto para los individuos como para las instituciones, las bajas pueden acarrear más inconvenientes que ventajas, para los primeros al suponer a veces el cese de los derechos adquiridos, para las segundas, por ejemplo para 
los propios municipios, al perder población, estando el financiamiento ligado al número de habitantes del mismo. Asimismo hay que entender la utilización de las bajas como corrector de la sobrestimación de las altas, para comprender la raíz de buena parte de la incertidumbre actual, incluso en aquellos movimientos identificados como bajas. De este modo, con el objetivo de combatir la sobreestimación y las duplicaciones de las altas de las que se tenía constancia y que acababan inflando los datos del Padrón Continuo, a partir de 2004 se establecieron las llamadas "bajas per inclusión indebida" y, a partir de 2006, las "bajas por caducidad". Las primeras correspondían a los procedimientos de baja de oficio llevados a cabo por los ayuntamientos (cuando se constata que la persona anteriormente empadronada ya no reside en el domicilio acreditado y que no consta su residencia en ningún otro municipio español) y que, a efectos de la EVR, son tratadas como emigraciones al extranjero de las que se desconoce el país de destino. Las segundas, son el producto de la modificación legislativa introducida por la Ley 14/2003 en la Ley Reguladora de Bases de Régimen Local por la que se establece que los extranjeros no comunitarios sin autorización de residencia permanente tienen la obligación de renovar su inscripción padronal cada dos años y, que en caso de no realizarse, los ayuntamientos tienen que declarar la caducidad de la inscripción. No obstante, el gran número de bajas producidas el primer año de su aplicación en 2006 para algunos municipios, tuvo como consecuencia que algunas veces, las bajas finalmente publicadas fueran el fruto de la negociación entre los ayuntamientos y el INE, levantando justificadas sospechas sobre la calidad de los datos. Para finalizar, deberemos tomar en cuenta qué parte del incremento del registro de las bajas se debe al afloramiento que provoca la mejora estadística -la diferente diligencia en el registro de las bajas establecería además desigualdades geográficas que se traducirían en la estimación de la emigración-, y qué otra a la atribución de bajas por caducidad o por inscripción indebida imputadas a la emigración exterior, cuando pueden tan sólo deberse al aumento de la migración interna debida a la crisis, o incluso a la simple corrección de altas que nunca significaron realmente una residencia real.

Junto con la EVR, existe el Padrón de Españoles Residentes en el Extranjero (PERE) igualmente elaborado por el INE, que permite el seguimiento indirecto de la evolución de la emigración española. Aunque en esta ocasión se ha decidido utilizar exclusivamente la EVR y no cotejar sus resultados con los del PERE, no queremos dejar de señalar algunas de sus limitaciones. El principal problema que presenta es que al tratarse de un registro de efectivos y no de flujos, la variación entre un año y otro de la población empadronada en el extranjero depende de la mortalidad y la natalidad tanto como de la emigración y la inmigración, o la adquisición de la nacionalidad (española o de un segundo país), y que recoge toda la población residente antes de la crisis económica, presentando también un subregistro endémico. Con esta fuente pues, multiplicamos los riesgos de sesgo que deberíamos controlar para dar como buenas las cifras que se producen. Además, como ya han señalado diversos autores (Garrido, 2013; González-Ferrer, 2013a), la Ley de la memoria histórica aprobada el 2007, que otorga la nacionalidad española a los descendientes de la 
emigración forzada entre el 18 de julio de 1936 y el 31 de diciembre de 1955 ha incrementado este Censo, sin ni tan solo la necesidad de que produzca ningún movimiento migratorio.

En este trabajo, lejos de abordar el subregistro, se pretende minimizar cierta confusión (sobre todo entre algunos medios de comunicación) alrededor de las cifras sobre la emigración española hacia el exterior, abordando esta nueva situación con los datos disponibles. Esto nos permite radiografiar una parte importante de la compleja emigración y/o movilidad actual.

\section{BAJAS Y EMIGRACIÓN DE ESPAÑOLES}

\subsection{El contexto migratorio en época de crisis}

Según los últimos datos disponibles (Tabla 1) la emigración de españoles para el año 2012, contaba con 56.392 bajas, de las cuales, la tercera parte correspondían a españoles nacidos en el extranjero, y un número indeterminado a hijos de migrantes nacidos en España con nacionalidad española ${ }^{3}$. Contando con todas las bajas de españoles (es decir, incluyendo a todos los españoles que habiendo emigrado ese año estuvieran relacionados con la reciente inmigración internacional), el saldo migratorio entre los españoles que llegaron y los que se fueron, es de 21.987 personas de menos. En el conjunto de la emigración salida desde España, que alcanzaba las 377.049 bajas, la cifra de la emigración de personas con nacionalidad española, representaba el 15\% de la emigración registrada, y si a esta le restamos los españoles nacidos en el extranjero (que asumimos en su inmensa mayoría extranjeros nacionalizados), el porcentaje desciende al $10 \%$. Aunque el saldo migratorio para la población extranjera siga siendo positivo, éste se ha visto reducido drásticamente en el último año, pasando de los 98.532 a 15.453 altas por encima de las bajas. Siendo el 2012 el primer año con saldos negativos para la migración internacional en su conjunto, computando tanto españoles como extranjeros. Pese a ello el saldo negativo para los españoles nacidos en España, tan sólo asciende a 19.908 salidas de más. ¿Por qué centrarse en los flujos de españoles, cuando sigue siendo mucho menor su relevancia numérica?

${ }^{3}$ Las estadísticas sobre Concesiones de nacionalidad española por residencia del Ministerio de Justicia sólo permiten aproximarnos de forma parcial a los procesos de solicitud, concesión y denegación de la nacionalidad. Según los datos disponibles desagregados por motivo de concesión, el número de nacionalizaciones por nacimiento fue de 35.786 entre 2004 y 2011, lo que representa sólo el 5,8\% de las 617.400 habidas en ese mismo periodo. Las concesiones tras dos años de residencia $(71,9 \%) \mathrm{y}$, en mucha menor medida, por matrimonio $(12,1 \%)$, han sido las principales vías de acceso a la nacionalidad por residencia. 
Tabla 1. Inmigración, emigración exterior y saldo migratorio según nacionalidad y país de nacimiento, 2007 - 2012

\begin{tabular}{|c|c|c|c|c|c|c|c|}
\hline & 2007 & 2008 & 2009 & 2010 & 2011 & 2012 & 2008-12 \\
\hline $\begin{array}{l}\text { Inmigración } \\
\text { exterior }\end{array}$ & 958.266 & 726.009 & 498.977 & 464.443 & 454.686 & 370.515 & 2.514 .630 \\
\hline $\begin{array}{l}\text { Nacionalidad } \\
\text { extranjera }\end{array}$ & 920.534 & 692.228 & 469.342 & 431.334 & 416.282 & 336.110 & 2.345 .296 \\
\hline $\begin{array}{l}\text { Nacionalidad } \\
\text { española }\end{array}$ & 37.732 & 33.781 & 29.635 & 33.109 & 38.404 & 34.405 & 169.334 \\
\hline $\begin{array}{l}\text { País de } \\
\text { nacimiento } \\
\text { España }\end{array}$ & 19.010 & 17.068 & 15.887 & 15.658 & 18.678 & 17.767 & 85.058 \\
\hline $\begin{array}{l}\text { País de } \\
\text { nacimiento } \\
\text { extranjero }\end{array}$ & 18.722 & 16.713 & 13.748 & 17.451 & 19.726 & 16.638 & 84.276 \\
\hline $\begin{array}{l}\text { Emigración } \\
\text { exterior }\end{array}$ & 227.065 & 266.460 & 323.641 & 373.954 & 370.540 & 377.049 & 1.711 .644 \\
\hline $\begin{array}{l}\text { Nacionalidad } \\
\text { extranjera }\end{array}$ & 198.974 & 232.007 & 288.269 & 336.676 & 317.699 & 320.657 & 1.495 .308 \\
\hline $\begin{array}{l}\text { Nacionalidad } \\
\text { española }\end{array}$ & 28.091 & 34.453 & 35.372 & 37.278 & 52.841 & 56.392 & 216.336 \\
\hline $\begin{array}{l}\text { País de } \\
\text { nacimiento } \\
\text { España }\end{array}$ & 22.527 & 25.888 & 25.550 & 26.693 & 37.928 & 37.675 & 153.734 \\
\hline $\begin{array}{l}\text { País de } \\
\text { nacimiento } \\
\text { extranjero }\end{array}$ & 5.564 & 8.565 & 9.822 & 10.585 & 14.913 & 18.717 & 62.602 \\
\hline $\begin{array}{l}\text { Saldo } \\
\text { migratorio } \\
\text { exterior }\end{array}$ & 731.201 & 459.549 & 175.336 & 90.489 & 84.146 & -6.534 & 802.986 \\
\hline $\begin{array}{l}\text { Nacionalidad } \\
\text { extranjera }\end{array}$ & 721.560 & 460.221 & 181.073 & 94.658 & 98.583 & 15.453 & 849.988 \\
\hline $\begin{array}{l}\text { Nacionalidad } \\
\text { española }\end{array}$ & 9.641 & -672 & -5.737 & -4.169 & -14.437 & -21.987 & -47.002 \\
\hline $\begin{array}{l}\text { País de } \\
\text { nacimiento } \\
\text { España }\end{array}$ & -3.517 & -8.820 & -9.663 & -11.035 & -19.250 & -19.908 & -68.676 \\
\hline $\begin{array}{l}\text { País de } \\
\text { nacimiento } \\
\text { extranjero }\end{array}$ & 13.158 & 8.148 & 3.926 & 6.866 & 4.813 & -2.079 & 21.674 \\
\hline
\end{tabular}

Fuente: EVR (INE), elaboración CED

Un vistazo al gráfico 1 puede darnos una pista. Mientras que la inmigración internacional descendía precipitadamente ya desde 2007 hasta 2009 (un $48 \%$ ), acusando la explosión de la burbuja inmobiliaria, y la emigración de 
extranjeros parecía que el año 2010 había alcanzado un máximo con 336.676 salidas, el comportamiento de los flujos de salida de españoles (nacidos en España y nacionalizados) era el opuesto: en sus inicios apenas sufrieron el impacto de la crisis en el caso de los nacidos en España disparándose en cambio a partir del último año 2010, mientras que la emigración de los españoles nacidos en el extranjero, pese a registrar un incremento continuado desde 2008, lo hizo en mucha menor medida que la emigración de extranjeros, y también experimenta un incremento para los últimos años. Las razones de ese casi paralelismo pueden ser, al margen del registro, muy diferentes. Nuestra hipótesis es que la emigración de españoles nacidos en España revela las consecuencias no de la crisis económica ligada al boom de la construcción sino de la aplicación de las políticas de austeridad, que se dejan sentir a partir de mediados de 2010 (fecha en la que el gobierno Zapatero admite la gravedad de la crisis). Es decir, refleja la crisis de la deuda pública y el impacto que sobre el empleo están teniendo las políticas de ajuste económico (Cachón, 2012).

\section{Gráfico 1. Inmigración y emigración exterior según nacionalidad y país de nacimiento, 2007-2012}

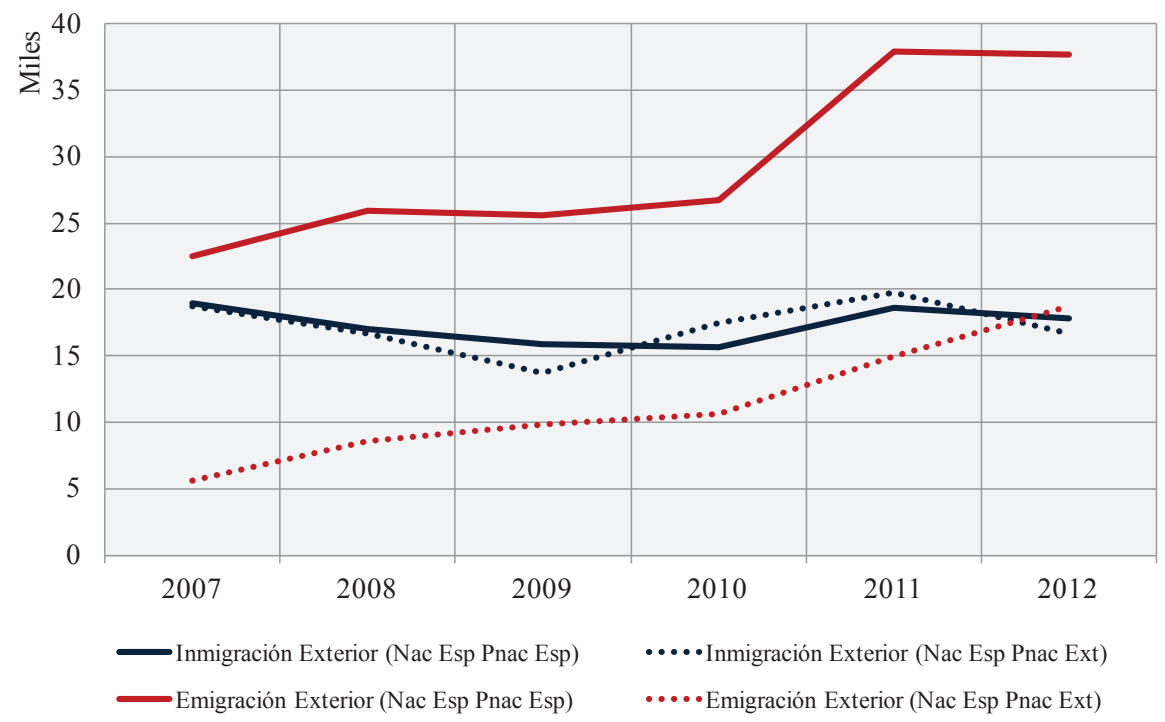

Fuente: EVR (INE), elaboración CED

El comportamiento de los flujos ha sido similar al experimentado en países de nuestro entorno y consistente con la literatura académica que ha abordado el efecto de los ciclos económicos sobre los procesos migratorios (Beets y Willekens, 2009; OECD, 2009b). De este modo, la salida de extranjeros estaría más vinculada a la crisis surgida en 2008, tras el estallido de la burbuja inmobiliaria. Esto se explicaría por diversos factores, entre los que 
sobresale, en primer lugar, el impacto diferencial del desempleo en la población inmigrante. Los trabajadores inmigrantes se vieron afectados por el paro antes y más intensamente que la población española debido fundamentalmente a que los primeros tienden a estar ocupados en empleos del mercado de trabajo secundario, en sectores caracterizados por una elevada precariedad e inestabilidad (Cebrián et al., 2010). La falta de capital social sería un segundo factor que, en conjunción con una débil cobertura del sistema de bienestar (Callejo et al., 2011), habría impedido a muchos inmigrantes -especialmente aquellos menor tiempo de residencia en España- hacer frente a periodos de desempleo prolongado o de disminución de ingresos. En correspondencia a esta situación, la emigración de retorno o la re-emigración a terceros países se plantea como una estrategia individual y familiar para sortear la crisis y alentada tanto en los países de origen y de destino (Bastia, 2011; Bocagni y Lagomarsino, 2011).

Pero si, como se ha señalado, la respuesta a la crisis por parte de la población extranjera -medida a partir de la evolución del paro y en la propia emigración- constata la diferente vulnerabilidad o resiliencia de la misma (Papademetriou y otros, 2010; Rogers, 2009) también plantea dilemas de política relacionadas con el uso de la inmigración como una solución a la cada vez mayor incertidumbre y segmentación del mercado de trabajo (Meardi et al., 2012). Precisamente, ésta ha sido unas de las primeras cuestiones abordadas en la literatura académica más reciente. Desde una perspectiva histórica, diversos autores han examinado el efecto de anteriores crisis sobre los patrones y políticas migratorias (Castles y Vezzoli, 2009; Martin, 2009; Green y Winters, 2010). En esta línea, la «teoría de búfer» que postula que el retorno o reemigración de extranjeros -junto al descenso salarial de la población nacional- tendría como resultado una eventual contratación de trabajadores nacionales, pierde validez en el caso español (Dobson et al., 2009; Blanchard et al., 2013). En efecto, los datos de desempleo mostrarían la escasa incidencia de este postulado, debido en gran parte a la paralización de la inversión en el sector de la construcción y obra pública, ésta última finalizada tras la ejecución del Plan Español para el Estímulo de la Economía y Empleo y su sucesor, el Plan de Economía Sostenible (popularmente conocidos como Plan E). Junto a ello, también se encuentra una política de austeridad cada vez más agresiva con recortes generalizados en el sector público, y una con una especial incidencia ya no sólo entre los jóvenes (y no tan jóvenes) de cualificación baja y/o media, sino entre aquellos de instrucción más elevada. Aunque algunos de estos últimos ya protagonizaban la emigración (principalmente circular) de españoles antes de la crisis, ésta se ha visto claramente incrementada debido a la falta de oportunidades laborales de cualificación (y bien remuneradas), y a lo que parece un abandono prematuro de la denominada economía o sociedad del conocimiento por parte de España (Alba et al., 2013). En este sentido, la evolución de la variación interanual del paro en España por nacionalidad (representado en el gráfico 2) puede darnos pistas sobre el efecto de esas tres fases: 1) Primer impacto de la crisis con fuerte sacudida tanto para nacionales como para extranjeros, debido a la burbuja inmobiliaria; 2) relativa estabilización durante el primer trimestre del 2010 y el segundo 
del 2011, y 3) crecimiento a partir del segundo trimestre de 2011, mucho más agudizado para los españoles desde el primer trimestre de 2012.

\section{Gráfico 2. Población parada según nacionalidad. Variación interanual (\%), 2007TI-2013TI}

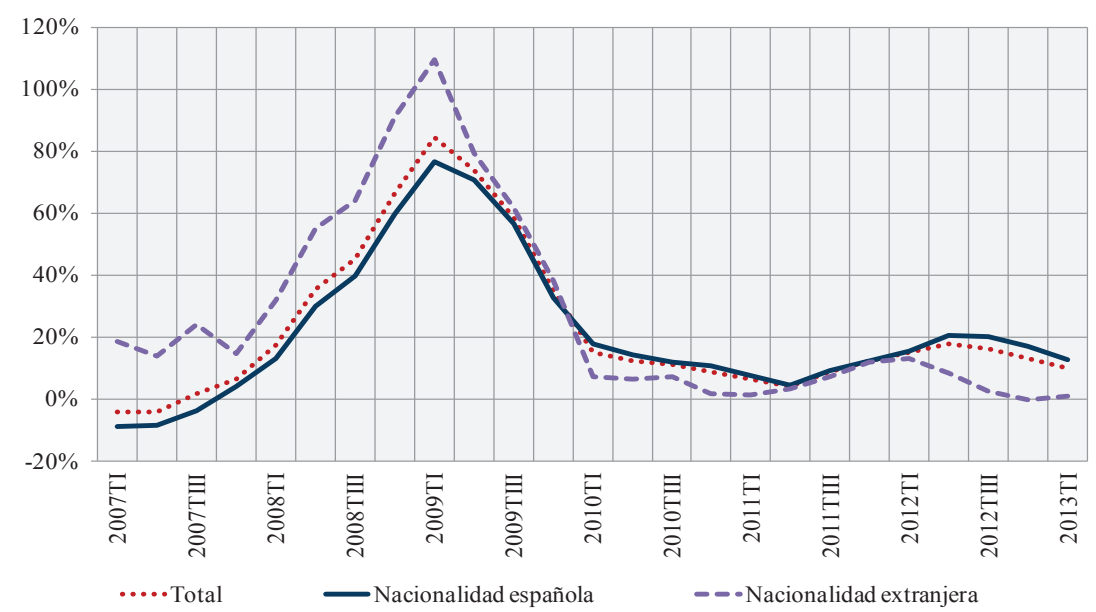

Fuente: EVR (INE), elaboración CED

Mientras, la emigración de la población española nacida en el extranjero puede estar mediatizada por el ritmo de nacionalizaciones, que cuenta con un gran potencial, tanto para aquellas nacionalidades que sólo precisan de dos años de residencia legal continuada en el país para obtenerla, especialmente para los Iberoamericanos, como para el resto que necesita de 10 años, en particular para los africanos cuyos flujos en muchos casos fueron de mayor antigüedad que los de los latinoamericanos, y que por tanto ahora también cuentan con un potencial significativo de candidatos a la nacionalización. De hecho podríamos creer, que parte de la retención de movimientos de salida, corresponde a esos ciudadanos extranjeros que esperan obtener pronto la nacionalidad española, no tanto para proceder a un retorno "con red", sino para poder desplazarse sin trabas a terceros países, por lo menos los pertenecientes al espacio Schengen.

\subsection{Los perfiles por sexo y edad de la emigración por nacionalidad}

Los perfiles por sexo y edad de la emigración según la nacionalidad (española y no española) y el lugar de nacimiento de los españoles y su evolución entre el primer año de la crisis y el último disponible, acaba siendo reveladora de la diferente naturaleza de esa emigración (Gráfico 4). La primera diferencia que salta a la vista en la composición por sexo de las corrientes emigratorias es la práctica 
igualdad entre sexos para los españoles, tanto en 2008 como en 2012, salvo una ligera sobrerrepresentación de los hombres maduros, a partir de los 45 años. En cambio para los extranjeros, los flujos de salida siempre han sido superiores para hombres que para mujeres, precisamente en las edades centrales. Ello puede imputarse precisamente al mayor impacto que la crisis económica ha tenido sobre los hombres extranjeros en el desempleo, al encontrarse muchos de ellos ocupados en el sector de la construcción y derivados, mientras que las mujeres concentradas en el sector servicios y trabajo doméstico han podido sobrellevar la crisis mejor. En cuanto a la estructura por edad de la población, primero llama la atención el registro de menores: su enorme proporción entre los españoles nacidos en España y su caída al año de edad entre los extranjeros, nos sugiere que buena parte de esos efectivos son descendientes de migrantes extranjeros nacidos en España a los que se concedió la nacionalidad española sea en el momento de nacer -mayoría de descendientes de migrantes de Ecuador, Colombia o Bolivia, por ejemplo-, sea porque sus padres ya obtuvieron la nacionalidad española -el caso de población marroquí-, o fuera por lo menos hijo de un ciudadano español no relacionado con la inmigración reciente.

En todo caso, y como veremos más adelante, esa presencia de menores nos ayuda a discriminar el tipo de flujo con el que nos encontramos. Por último, entre los emigrantes de nacionalidad española nacidos en el extranjero, los perfiles tanto para hombres como para mujeres son de mayor edad -ya que a la biografía migratoria hay que sumar los años en que se ha tardado en obtener la nacionalidad-, pero también para descendientes de emigrantes españoles que habiendo inmigrado previamente a España, hayan decidido retornar debido a la crisis. Eso explicaría la presencia entre las principales destinaciones de países que no habiendo destacado en la inmigración reciente, sí lo hicieran en la emigración transatlántica española del siglo XX, como veremos a continuación.

\section{Gráfico 3. Distribución por sexo y edad de la emigración exterior según nacionalidad y país de nacimiento, 2008-2012 Nacionalidad extranjera}

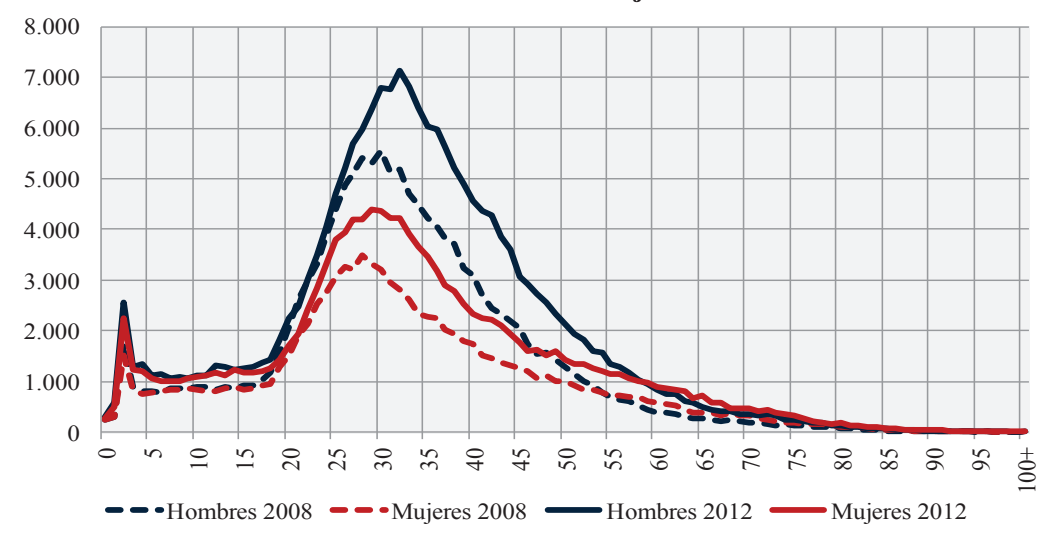


Nacionalidad Española-País de nacimiento España

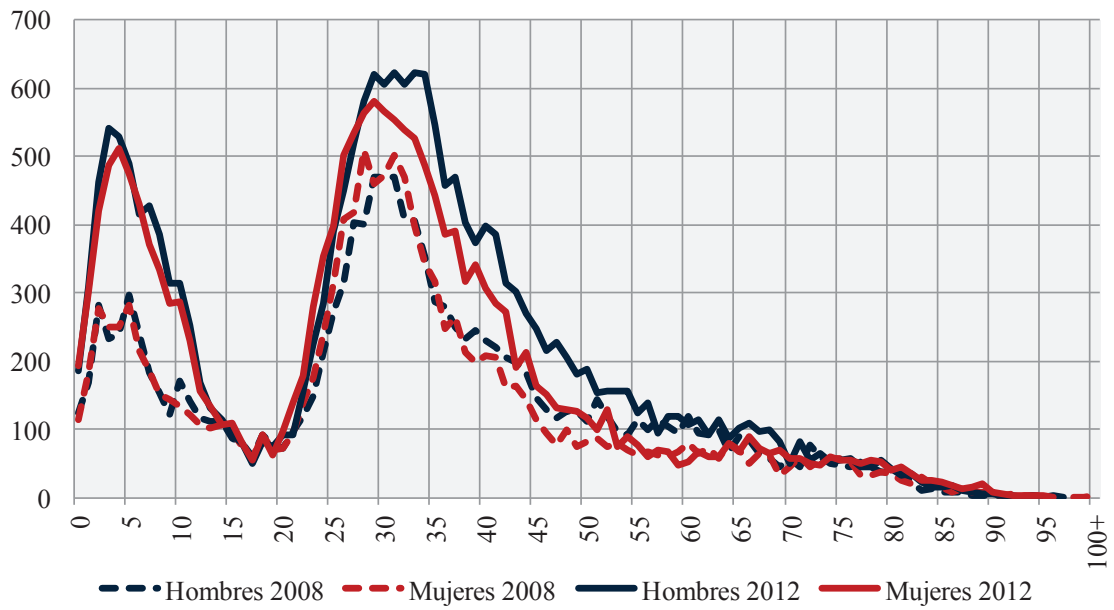

Nacionalidad Española-País de nacimiento extranjero

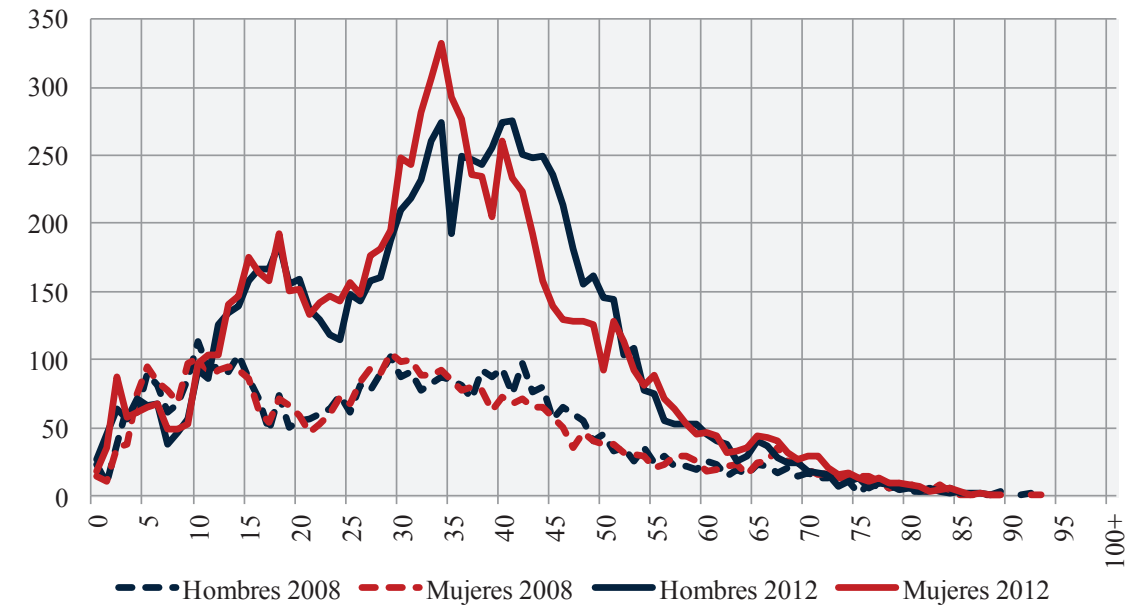

Fuente: EVR (INE), elaboración CED 


\section{4. ¿DE DÓNDE PARTEN?}

El análisis de la distribución territorial de la emigración refleja un mapa muy desigual de las salidas hacia el exterior desde las provincias españolas al igual que diferencias relevantes, tanto en términos absolutos como relativos, entre la población de nacionalidad española nacida en España y aquella nacida en el extranjero.

Mapa 1. Emigración exterior española según país de nacimiento, 2008-2012
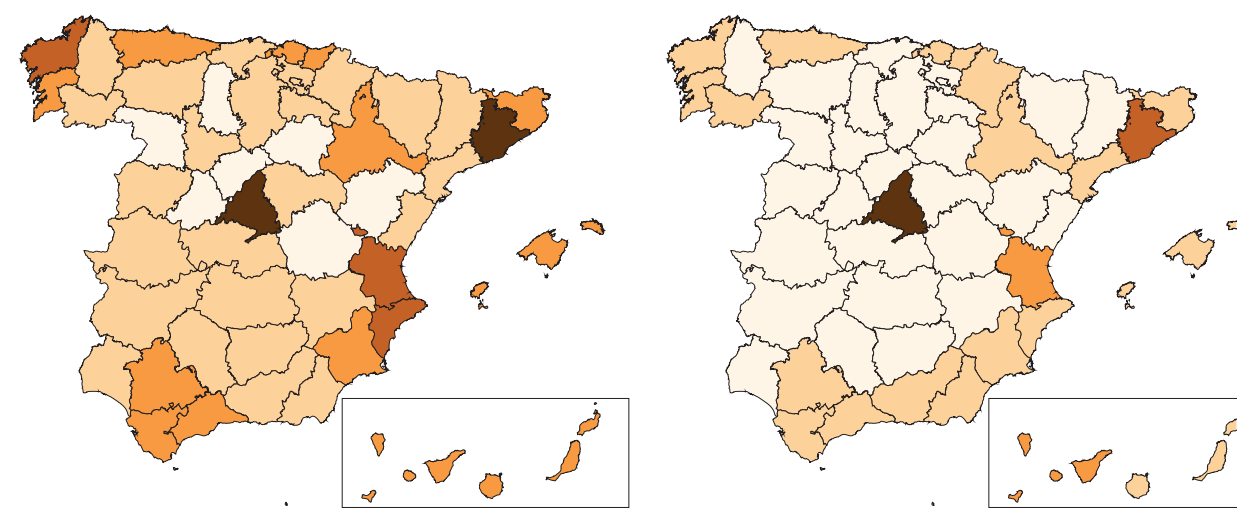

Fuente: EVR (INE), elaboración CED

Junto a las provincias de Madrid y Barcelona como principales puertas de salida de los emigrantes españoles (ambas aglutinan más del 38\% del total), Valencia, Alicante, A Coruña, Santa Cruz de Tenerife, Málaga, Pontevedra, Islas Baleares, Guipúzcoa y Murcia concentran el grueso de la emigración exterior desde el comienzo de la crisis. Dos de cada tres emigraciones se han producido desde estas once provincias. Aunque el resto del territorio español no se ha mantenido al margen de la emigración, su magnitud ha sido muy inferior en 30 provincias, donde no se han superado los 2.500 movimientos hacia el exterior en estos cinco años. El lugar de nacimiento revela mapas provinciales dispares en términos absolutos y relativos. La distribución provincial de las salidas de la población nacida en España aparece más repartida, sumándose a Madrid, Barcelona, Valencia, Santa Cruz de Tenerife y Alicante (que suman la mitad de todas las salidas), 16 provincias desde donde se han producido entre 2.500 y 5.000 emigraciones. En cambio, la emigración de españoles nacidos en el extranjero se ha concentrado básicamente en Madrid, Barcelona y, en menor medida, en Valencia y Santa Cruz de Tenerife, seguidas por 19 provincias en las que se registraron entre 500 y 2.500 salidas. El análisis territorial muestra claramente que las principales provincias de destino de las migraciones internas (en el caso de la población nacida en España) así como las puertas de entrada de la inmigración 
internacional (para los nacidos en el extranjero), se han convertido también en las principales puertas de salida hacia el exterior en el actual contexto de crisis. Al menos así se deriva del comportamiento emigratorio diferencial de las provincias de interior y de aquellas (situadas en su mayoría en el arco mediterráneo y las islas) que experimentaron un fuerte crecimiento de la inmigración extranjera, cuyo asentamiento territorial estuvo principalmente asociado a la expansión de los sectores de la construcción, el turismo y la agricultura intensiva.

Mapa 2 Tasas de emigración (por mil) de la población con nacionalidad española (mayor de 65 años) según país de nacimiento, 2008-2012

\section{País de nacimiento España}

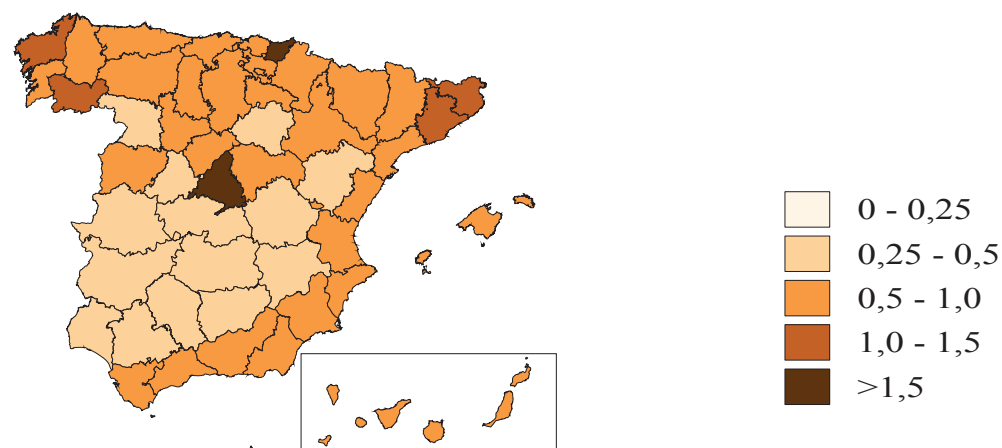

\section{País de nacimiento extranjero}

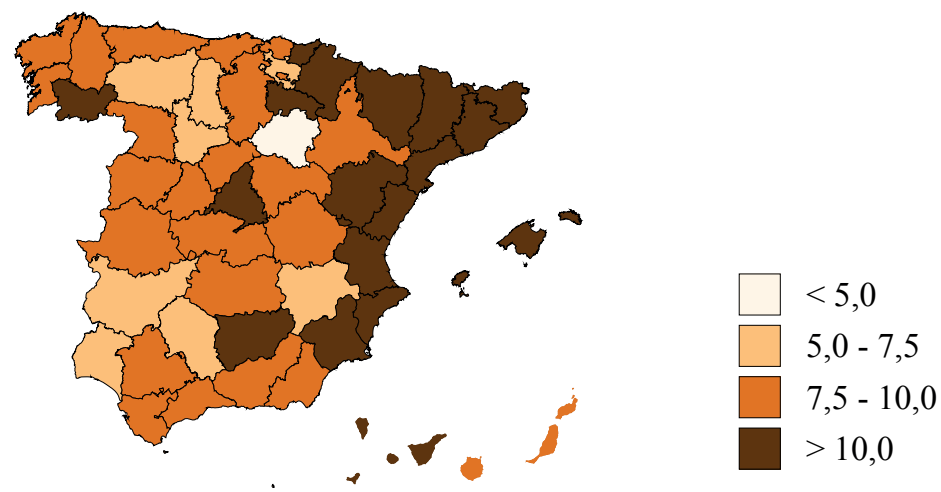

Fuente: EVR (INE), elaboración CED 
Las tasas de emigración de la población española (menor de 65 años) evidencian, de entrada, la desigual intensidad del fenómeno según el lugar de nacimiento y provincia de origen de los flujos (Mapa 2). Así, las tasas de emigración de los nacidos en España sólo alcanzan a superar una migración por cada 1.000 residentes en seis provincias españolas. En cambio, las tasas de los españoles nacidos en el extranjero oscilan entre 4 (Soria) y 14 (Lérida) migraciones anuales por cada 1000 residentes, quedando, por tanto, muy lejos de las tasas emigratorias que puede llegar a registrar la población con nacionalidad extranjera.

\section{Mapa 3. Emigración exterior española según país de nacimiento. Variación porcentual, 2008-2012}

\section{País de nacimiento España}

2008/09

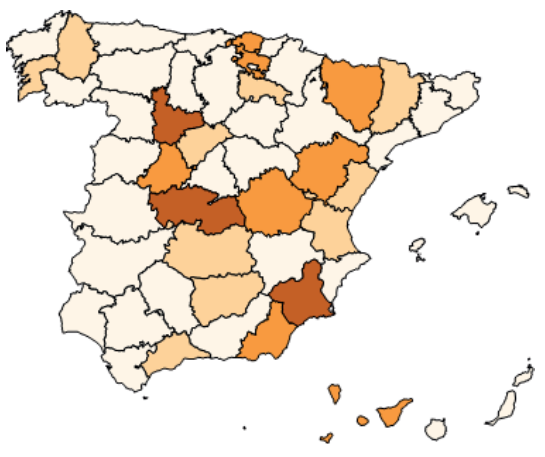

2009/10

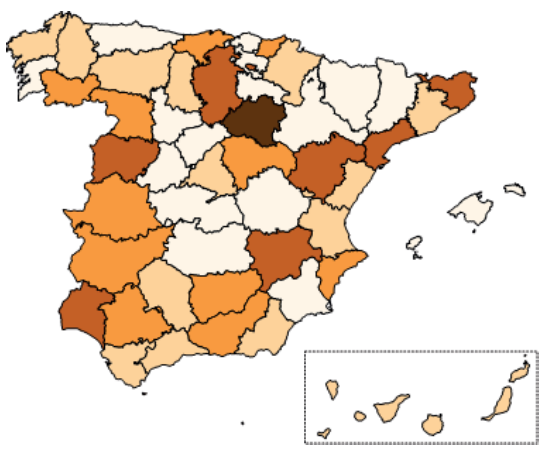

\section{País de nacimiento extranjero}

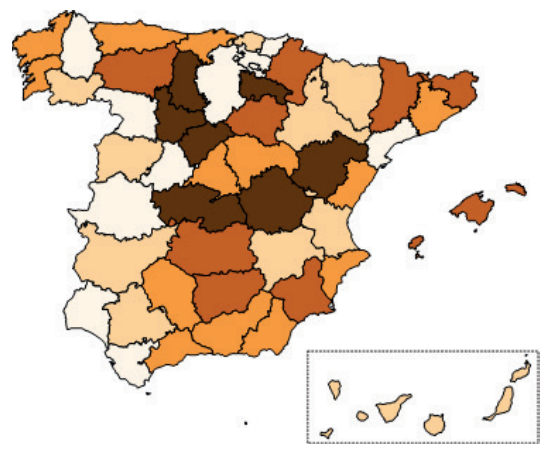

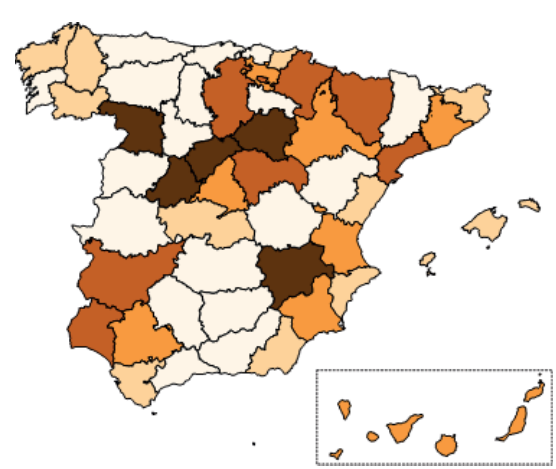


2010/11
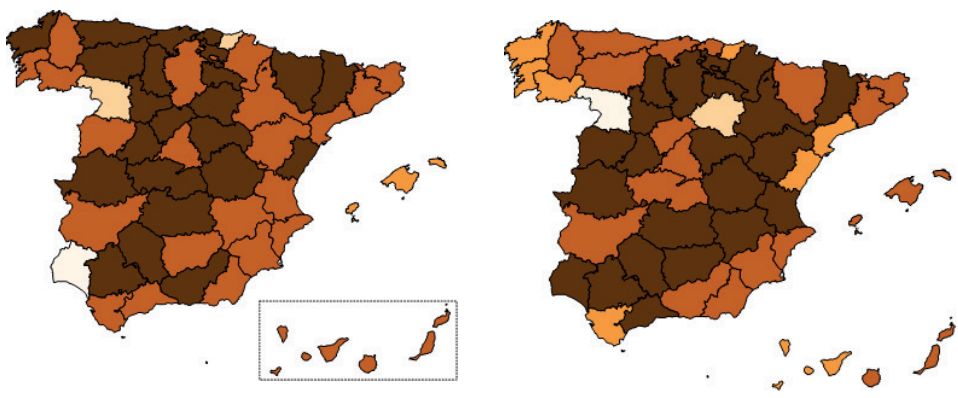

2011/12
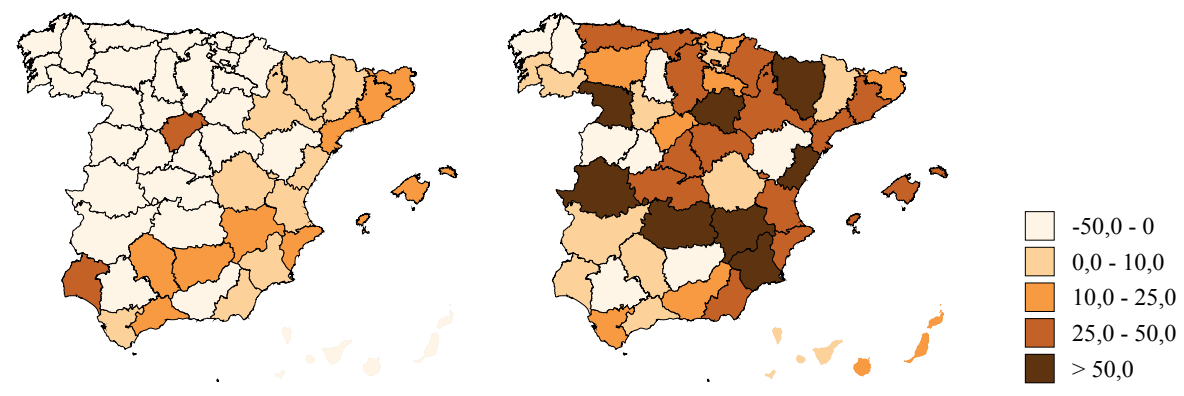

Fuente: EVR (INE), elaboración CED

El examen de las salidas revela claras diferencias según el lugar de nacimiento de los emigrantes españoles respecto a la temporalidad con que han tenido lugar (Mapa 3). Mientras que la emigración de españoles nacidos en el extranjero experimentó fuertes crecimientos ya desde el inicio de la crisis en 2008 (con incrementos superiores al 25\% en 16 provincias) la emigración de españoles nacidos en España comenzó a hacerse notar parcialmente en 2010 y ya de forma generalizada en 2011, con incrementos similares a las de los nacidos en el extranjero en 48 de las 52 provincias. Los mapas correspondientes a este último año muestran la estabilización en las salidas en el caso de los nacidos en España y la tendencia creciente de los nacidos en el extranjero.

Esta relativa falta de sincronía en la emigración entre ambos grupos sería reflejo de la secuencia de la crisis y de su impacto en población con nacionalidad española. Como se viene diciendo, el incremento generalizado de la emigración de los nacidos en España en 2011 podría interpretarse como una de las consecuencias de las políticas de ajuste y el persistente crecimiento del desempleo. 
Mapa 4. Saldo exterior según nacionalidad y país de nacimiento, 2003-2012

2003/07

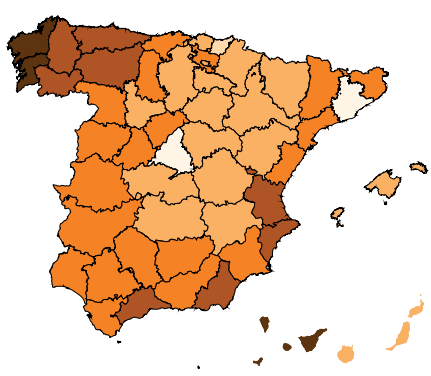

2008/12

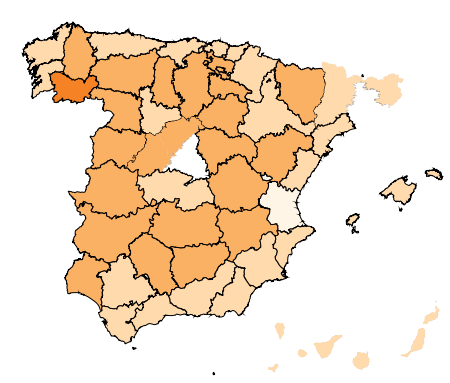

2008/12

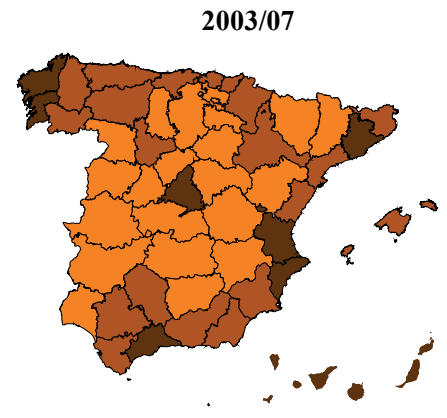

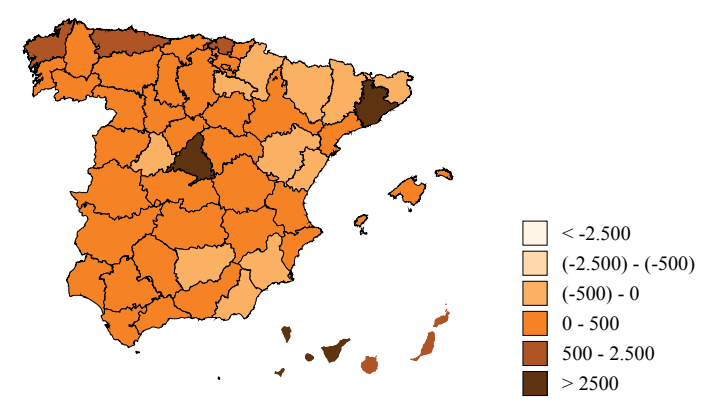

Fuente: EVR (INE), elaboración CED

Conviene recordar que, a pesar del impacto que ha tenido la crisis económica sobre los procesos migratorios, nuestro país no ha dejado de ser un receptor neto de inmigración internacional hasta este año, registrándose un balance positivo de 809.520 migrantes entre 2008 y 2011, cifras que en cualquier caso se alejan bastante de las vividas en plena fase expansiva (+2.710.491 entre 2004 y 2007). Lo novedoso sería, como se dijo, la incipiente emigración de españoles que, para los nacidos en España, arrojaría un saldo negativo de 68.676 personas. A nivel territorial, todas las provincias (a excepción de Ourense) se verían afectadas por la pérdida de población, aunque de forma muy desigual, especialmente si te tiene en consideración las dinámicas previas a la crisis (Mapa 4) y que, en provincias como A Coruña, Pontevedra, Santa Cruz de Tenerife o Alicante ha supuesto una dramática inversión de sus saldos exteriores de población española nacida en España. 


\section{DESTINOS PRINCIPALES DE LA EMIGRACIÓN EXTERIOR SEGÚN NACIONALIDAD}

Para contextualizar debidamente la migración española y neohispánica, se ha decidido comparar en este y el siguiente apartado el comportamiento de la población extranjera. Pero antes de comparar los diferentes destinos según la nacionalidad, debemos recordar que para los extranjeros sólo disponemos del $13,3 \%$ del conjunto de las 1.495.308 bajas. Mientras que para los españoles, como ya hemos comentado, pese a disponer de información completa de los destinos, estas están afectadas por una subestimación que se supone importante pero completamente desconocida. En todo caso, los principales países de destino según la nacionalidad (española o no española) y entre la primera el lugar de nacimiento (en España o fuera de ella) son reveladores (ver gráfico 3). No es de extrañar que mientras para los extranjeros los principales países de destino sean los países desde donde se originaron las corrientes migratorias, es decir, que se trate mayoritariamente, aunque no únicamente, de movimientos de retorno o arrastre, para las personas de nacionalidad española los países que encabezan la clasificación tengan poco o nada que ver con la inmigración internacional reciente. Con la finalidad de comprender mejor la relación de los destinos y el propio retorno de vemos también tener en cuenta que una condición previa para el mismo es la propia situación económica y política del país de origen, que al fin y al cabo, es uno de los factores decisivos para entender la decisión de retorno o reemigración para los extranjeros y la propia trayectoria migratoria de la población neohispánica.

Gráfico 4. Emigración exterior según nacionalidad, país de nacimiento y destinos principales, 2008-2012

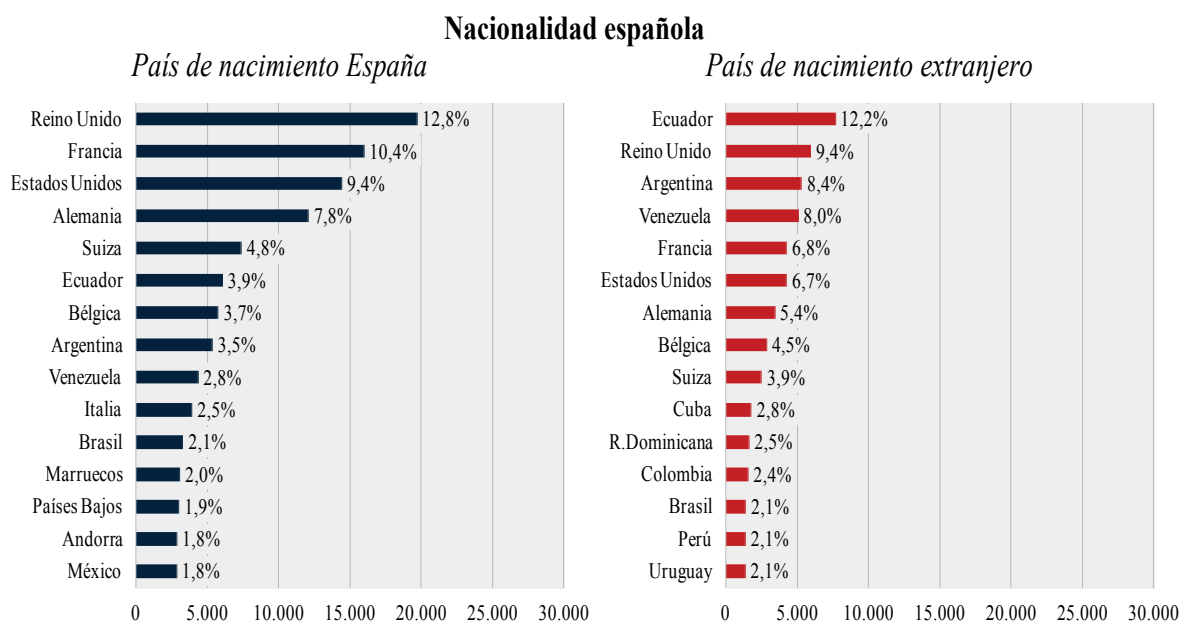

EMPIRIA. Revista de Metodología de Ciencias Sociales. N. ${ }^{\circ}$ 29, septiembre-diciembre, 2014, pp. 39-66. ISSN: 1139-5737, DOI/empiria.29.2014.12940 


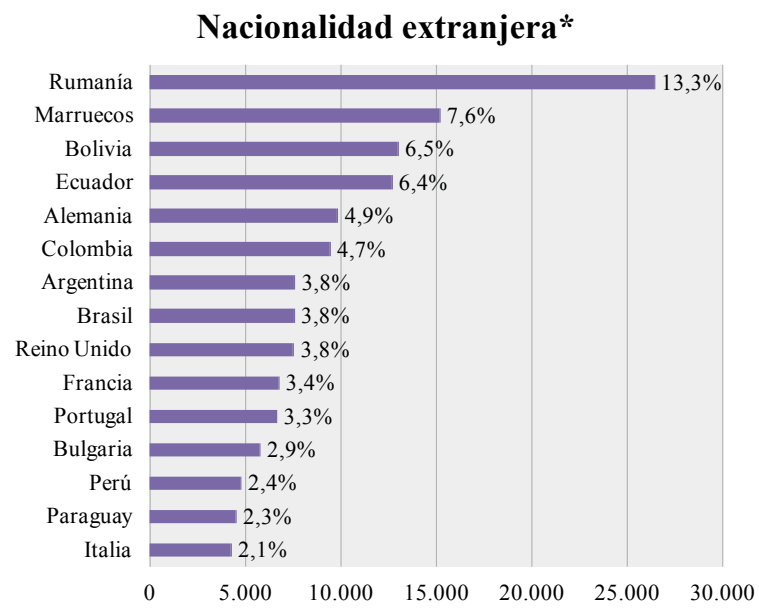

Fuente: EVR (INE), elaboración CED (*) Sólo destinos conocidos

De este modo, los cuatro primeros países de emigración para los extranjeros son Rumanía, Marruecos, Bolivia y Ecuador, coincidiendo con el origen de las principales poblaciones migrantes en España, y sumando ellas solas un tercio de todas las bajas de extranjeros en los que se conoce el país de destino. Para los españoles nacidos en España, sin embargo, los cuatro primeros países son: el Reino Unido, Francia, Estados Unidos y Alemania, que representan por si solos el $40 \%$ de todas las salidas. La inclusión de países origen de la última inmigración internacional en lugares menos significativos como Ecuador o Marruecos, o de otros europeos como Bélgica, inferidos gracias a la estructura por edad de la migración que han recibido esos países se corresponde con la emigración de arrastre de los descendientes y algunos cónyuges españoles de los migrantes extranjeros. Por último, encontramos a los españoles nacidos en el extranjero, donde se mezclan los países que encabezan la migración de extranjeros y algunos de los destinos europeos e internacionales también destacados entre los españoles. De este modo, las cuatro primeras nacionalidades son: Ecuador, Reino Unido, Argentina y Venezuela.

\section{LA EMIGRACIÓN NEOHISPÁNICA SEGÚN LOS PAÍSES RECEPTORES}

Por último, como hemos avanzado, la observación de la distribución por edad de los flujos de extranjeros y españoles por lugar de nacimiento, llegada a los principales países destinatarios de la emigración española, resulta muy ilustrativa de lo que puede estar realmente sucediendo (Gráfico 5). Hemos tenido a bien utilizar el neologismo "neohispánico" para referirnos al conjunto de los 
movimientos que agrupan la emigración española (de nacidos en España), la de los extranjeros residentes en España, y la de aquellos extranjeros inmigrados que obtuvieron la nacionalidad española, aunque nuestro principal propósito sigue siendo resaltar la diferencia entre esos tres tipos de corrientes por nacionalidad y lugar de nacimiento.

El modelo de Gran Bretaña, que recordemos era el primer destino para la migración española nacida en España, muestra de qué manera estos flujos son superiores tanto a la de los extranjeros como a la de españoles nacidos en el extranjero, correspondiendo su estructura por edad con la imagen de la emigración de jóvenes que se ha popularizado en el imaginario colectivo. Mientras, los de nacionalidad extranjera destacan por la presencia de edades mayores, que pueden asociarse al retorno de emigrantes británicos o al efecto estadístico producido por las bajas consecuencia de la depuración de los datos de residentes comunitarios que se convierten en bajas atribuidas a la emigración, cuando de hecho pueden haberse producido mucho antes. También se diferencian esos flujos del de los migrantes españoles nacidos en el extranjero, donde encontramos desde nacionalizados latinoamericanos -especialmente colombianos-, hasta pakistaníes. Nada parecido a los perfiles de Francia o Bélgica, donde lo que destaca es la emigración de españoles nacidos en el extranjero, y el peso desproporcionado de los menores que corresponden a españoles nacidos en España, especialmente en el segundo país. En estos países nos encontramos muy probablemente con una predominancia de emigración de inmigrantes nacionalizados españoles y de su descendencia y en algunos casos cónyuges españoles. Para ser más exactos, nos hallamos frente a una presencia importante de población relacionada con la inmigración marroquí (llegada a España mayoritariamente de Marruecos, pero que no debe descartarse que lo fuera desde Francia o Bélgica). En este caso, la movilidad intraeuropea se da sobre todo por la existencia previa de redes migratorias y familiares para algunos orígenes determinados,

\section{Gráfico 5. Distribución por edad de la emigración exterior según nacionalidad, país de nacimiento y destinos principales. 2008-2012}
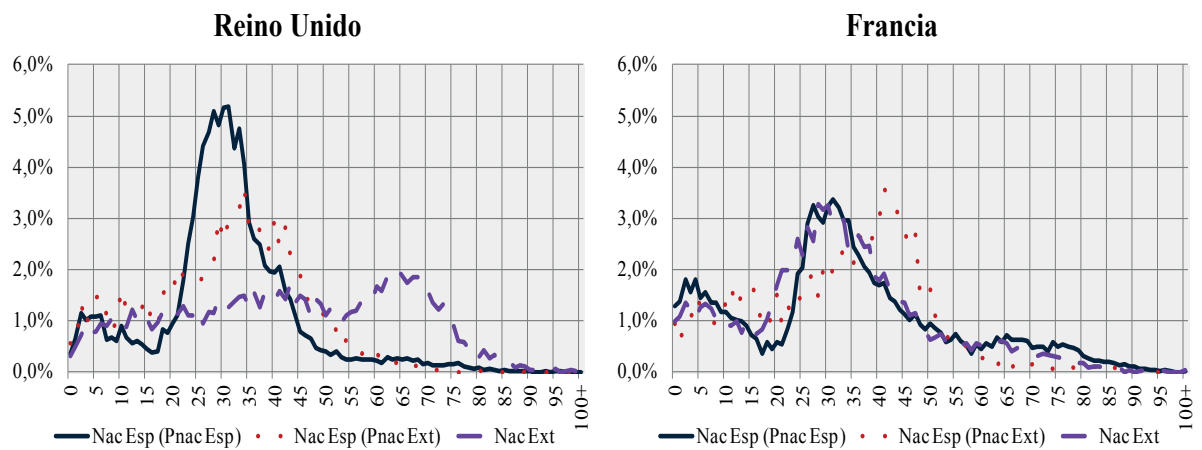

EMPIRIA. Revista de Metodología de Ciencias Sociales. N. ${ }^{\circ}$ 29, septiembre-diciembre, 2014, pp. 39-66. ISSN: 1139-5737, DOI/empiria.29.2014.12940 
Estados Unidos

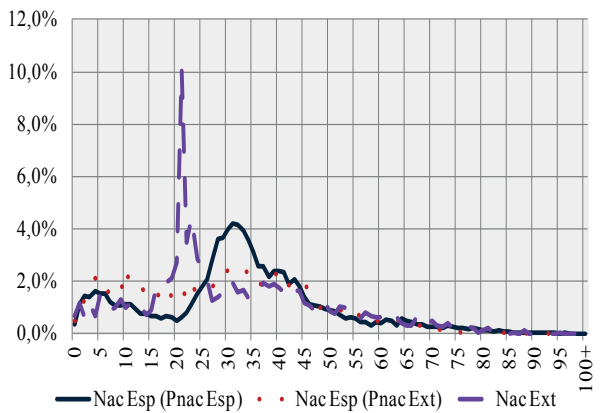

Suiza

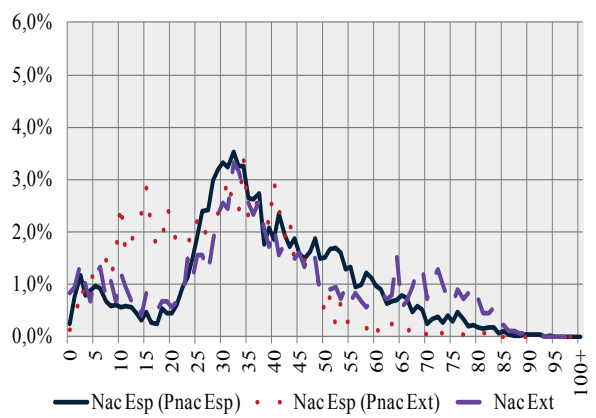

Alemania

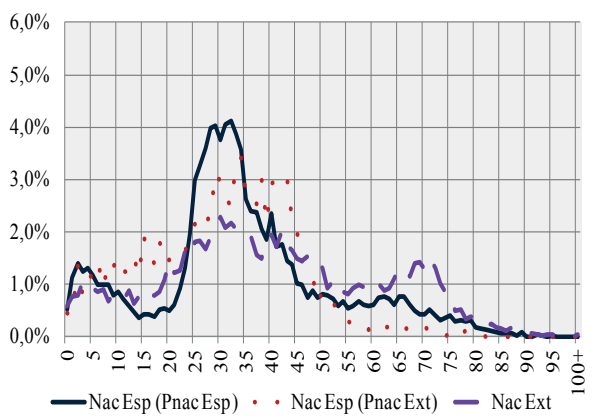

Bélgica

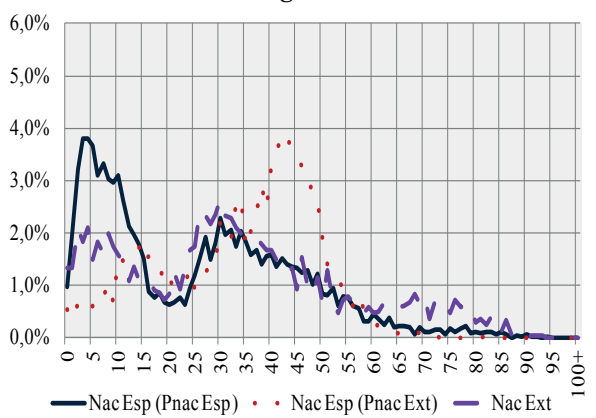

\section{Argentina}

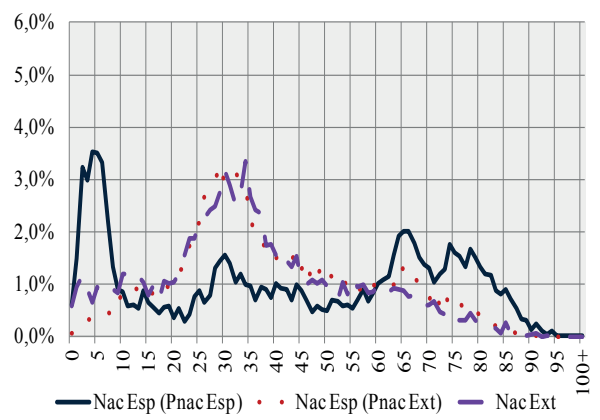

Fuente: EVR (INE), elaboración CED 
facilitando pues dicha movilidad y la hipotética inserción en el mercado laboral francés o belga. En los casos de Suiza y Alemania estos podrían estar combinando ambos tipos de flujo: el de jóvenes españoles y el de la inmigración nacionalizada española (asociada a la consabida migración de arrastre).

Es decir, una de las características a retener es que la migración se trata en parte también de una migración familiar, no tan sólo de jóvenes que se mueven a nivel individual, sin que podamos discernir cuántos de esos menores corresponden a los migrantes españoles nacidos en España y cuantos a españoles nacidos en el extranjero. Los últimos dos casos se sitúan en las antípodas: la migración dirigida a Argentina, donde el retorno, la emigración de arrastre y la relación con la antigua emigración española, determinan unos flujos, presentando la característica desproporción de menores en este caso para extranjeros nacidos en España (en su mayoría argentinos) pero del mismo modo una sobrerrepresentación no menos singular a edades mayores a partir de los sesenta y más. Para finalizar, en los Estados Unidos, destaca el pico debido a los 20 años para los extranjeros, relacionado con la legislación estadounidense sobre reagrupación familiar.

\section{CONCLUSIONES}

La narrativa con la que los medios de comunicación nos han explicado los movimientos emigratorios recientes, ha oscilado entre la tentación de seguir el guión del eterno retorno (marcado aquí por el ciclo económico) y el de la lectura futurista, del futuro como innovación (Augé, 2012). En ambas se explora la significación de la crisis económica en relación a los movimientos migratorios en el devenir histórico de España, acentuando el fatalismo la primera óptica, pero también la segunda, al presentar el futuro como acto fallido (aquello que hubiéramos podido ser). Sendas interpretaciones, se han utilizado como recurso dramático para dar contundencia a los titulares, por ejemplo: "Emigrantes de Segunda Generación", "La emigración a Alemania se dispara al nivel e hace 40 años", por un lado, o "Con las maletas preparadas" y "Cerebros de ida y vuelta", por otro, para ceñirnos únicamente al último año, en sólo una semana, y a un único medio de comunicación (El País). Las dos han buscado en el número, en el recurso a la demografía su solidez, su incontestabilidad, a pesar de chocar con la voz de alerta de los expertos, que han tendido a minimizar el fenómeno o a desplazar su interpretación no al pasado o al futuro, sino al presente (lo que no se está haciendo metodológica o políticamente).

Mientras, la mirada nostálgica del político se vuelve hacia el concepto de "diáspora". Ese engañoso esplendor que un PERE poco fiable parece brindarnos y que los programas de entretenimiento han encumbrado en nuestras noches insomnes, para mayor gloria del populismo. Esos "Españoles en el mundo", en los que se entremezcla la pesada deuda con el pasado que intentamos aplacar con la Ley de la Memoria histórica, y que carga con los sinsabores de la migración del siglo XX, junto con el fulgurante anuncio del futuro hecho presente que llamamos globalización que cuenta con la movilidad del siglo XXI --españoles 
en Shanghái o en Noruega-, o el escapismo simbolizado por las playas tropicales (destino final si ocurre el milagro). No todo ha sido responsabilidad española. Algunos de los países europeos receptores de inmigración, singularmente Alemania y el Reino Unido, están imitando el modelo de crecimiento de EE.UU. de los últimos treinta años, basado en la atracción tanto de mano de obra cualificada y mano de obra barata y flexible (Sommers y Woolfson, 2008). En este sentido, ambos mercados se alejan cada vez más de los modelos poscoloniales de contratación y del Gastarbeiter, y tienden hacia unos mercados laborales extremamente duales (Favell, 2008), donde ni siquiera un rápido descenso del desempleo y/o la escasez de mano de obra (el reciente caso alemán) se traduce en un incremento significativo de inmigración, y en algunos casos (en el caso alemán, pero también en el Reino Unido y los Países Bajos) en un aumento progresivo de la emigración (Van Dalen y Henkens, 2013). Mientras tanto, los gobiernos en el sur de Europa parecen transcurrir en una ambigüedad sobre cuáles son los objetivos de la política migratoria que deben adoptar y, como no, a quién o quienes deben servir estos, lo que para algunos (Plewa, 2009) explica por qué el ciclo de políticas de contratación de trabajadores extranjeros temporales ha venido repitiéndose en Europa desde mitad del siglo pasado.

¿En el caso español qué nos dicen los datos? El análisis de los flujos de emigración internacional, pese a las deficiencias señaladas, sí que ha resultado muy ilustrativo. Los datos parecen confirmar que además de la afectación diferente que había tenido la crisis económica por nacionalidad en cuanto al volumen de la emigración, también presenta una temporalidad diferente. Ello se explica porque la causa no es la misma: más aguda y concentrada en sus inicios en los extranjeros debido a la explosión de la burbuja inmobiliaria y su repercusión sobre el sector de la construcción y derivados, más desplazado el efecto de las políticas de austeridad que afectaría con mayor intensidad a los españoles. Con todo, y pese a su incremento, el monto de las salidas de españoles sigue siendo tan reducido que es arriesgado incluso hablar de fenómeno emergente ya que tal consideración implica la convicción de su futuro crecimiento sostenido. En todo caso, incluso bajo la categorización común de "migración de españoles", hemos podido ver que existen flujos muy diversos, aunque sólo hayamos podido atender a la composición por sexo y edad, el origen y destino de los mismos, y nada sepamos del nivel de instrucción o la composición familiar de los mismos. Para cubrir esa complejidad sin desmerecer el hecho de que unos se han nacionalizado españoles, y otros, descendientes de la inmigración internacional no sólo poseen la nacionalidad española, sino que también han nacido en España, hemos propuesto junto con la emigración de españoles nacidos en España no relacionados con la inmigración internacional, el calificativo de "neohispánica".

A pesar de que auguramos un aumento de la emigración durante 2013 en el que habrá jugado tanto el factor de expulsión del mercado laboral como las expectativas (inciertas) alimentadas por los medios políticos y de comunicación, o incluso a que asistamos a saldos migratorios negativos durante todo el quinquenio, no se prevé que ese movimiento de salida llegue a ser masivo, ni 
que se convierta en el factor esencial de la evolución demográfica española. Por otro lado, atendiendo a la composición por sexo y edad, tampoco parece equiparable a la emigración de antaño en su substrato social y estrategia migratoria. La mayor incertidumbre no se debe tanto a la falta de cobertura de los datos o a las dificultades de interpretación como a la evolución de la recesión producto del ajuste estructural. Si se sigue ahondando en la desregularización del mercado de trabajo español, en la destrucción empecinada de empleo, en el desmantelamiento de un sistema de I+D, instado por el FMI, $\mathrm{y}$ visto con complacencia por las autoridades europeas, seguramente las nuevas generaciones neohispánicas acabarán alimentando la circularidad de la mano de obra no sólo en distintos mercados de trabajo disfuncionales (estando España a la cabeza quizás, y siendo dicha circularidad más laboral -entre ocupado y desocupado- que geográfica), también en mercados claramente segmentados por la globalización de la oferta y la demanda de trabajadores (siendo los países ricos los principales abanderados), y algunos de ellos no menos disfuncionales. Así pues, y junto a la movilidad más voluntaria de la mano de obra más cualificada, también se extienden otras formas más extremas de movilidad transnacional, donde la flexibilidad prima, especialmente en los sectores de la agricultura y la construcción (Cremers, 2011). Esta última aparece como la solución óptima por el momento a un mercado laboral segmentado, y explicaría la evalución positiva por parte de la Comisión Europea al principio de la crisis: "employment and unemployment rates fluctuate more strongly for migrants than for non-migrants in response to changes in economic growth, suggesting not only that migrants' labour market outcomes are more sensitive to economic developments, but also that this provides an extra degree of flexibility" (EC, 2008: 51).

No obstante algunos espejismos no duran mucho, y durante este año 2013 las muestras de oposición o malestar frente a la emigración intraeuropea se han multiplicado, aunque con diferencias. Sirvan de muestra, las restricciones que países como Alemania, Francia, los Países Bajos y el Reino Unido están ejerciendo en los visados Schengen para ciudadanos europeos oriundos de Rumanía y Bulgaria, o el de Suiza con todos los ciudadanos europeos. 


\section{BIBLIOGRAFÍA}

ALBA, S., FERNÁNDEZ, A. y MARTÍNEZ, U. (2013): Crisis económica y nuevo panorama migratorio en España, Madrid, Fundación Primero de Mayo, 65

ÁLVAREZ, A. (2006): Nacionalidad de los hijos de extranjeros nacidos en España, Madrid, Ministerio de Trabajo y Asuntos Sociales

AUGÉ, M. (2012): Futuro, Buenos Aires, Adriana Hidalgo Editores

BASTIA, T. (2011): "Should I stay or should I go? Return migration in times of crises", Journal of International Development, 23(4), pp. 583-595

BLANCHARD, O., JAUMOTTE, F. y LOUNGANI, P. (2013): Labour Market Policies and IMF Advice in Advanced Economies during the Great Recession, SDN/13/02, International Monetary Fund

BEETS, G. y WILLEKENS, F. (2009): "The global economic crisis and international migration: An uncertain outlook", Vienna Yearbook of Population Research, pp. 19-37

BOCCAGNI, P. y LAGOMARSINO, F. (2011): "Migration and the global crisis: new prospects for return? The case of Ecuadorians in Europe", Bulletin of Latin American Research, 30(3), pp. 282-297

CABRÉ, A. (1999): El sistema català de reproducció, Barcelona, Proa

CABRÉ, A. y DOMINGO, A. (2014): “L'emigració des de Catalunya: aspectes demogràfics i prospectius". Barcelona, CIDOB

CACHÓN, L. (2012): "La inmigración de mañana en la España de la Gran recesión y después", Panorama Social, 16, pp. 71-83

BRUQUETAS, M., MARÍ-KLOSE, P., y MORENO, F. J. (2011): “Inmigración, crisis económica y Estado de Bienestar en España”, Documentación social, 162, pp. 209234

CASTLES, S. y VEZZOLI, S. (2009): "La crisi econòmica mundial i la migració: una interrupció temporal o un canvi estructural?", Paradigmes: economia productiva i coneixement, 2, pp. 68-75

CATALÁN, G. (2013): “Cerebros de ida y vuelta”, El País, disponible en http://elpais. com/elpais/2013/04/10/opinion/1365590300_644335.html, [consulta: 13-5-2013]

CEBRIÁN, J. A.; BODEGA, M. I.; MARTÍN-LOU, M. A., y GUAJARDO, F. (2010): "La crisis económica internacional y sus repercusiones en España y en su población inmigrante", Estudios Geográficos, 71(268), pp. 67-101

CREMERS, J. (2011): In Search of Cheap Labour in Europe. Working and Living Conditions of Posted Workers, Brussels, CLR/EFBWW/International Books

DE CASTRO, M.A. (2004): "Fuentes estadísticas sobre la inmigración”, Economistas, 99, pp. 128-145

DOBSON, J., LATHAM, A. y SALT, J. (2009): On the move? Labour Migration in Times of Recession, Policy Network Paper, London, Policy Network

DOMINGO, A. y RECAÑO, J. (2010a):»La inflexión en el ciclo migratorio internacional en España: impacto y consecuencias demográficas», en La inmigración en tiempos de crisis. Anuario de la Inmigración en España (edición 2009), Barcelona, CIDOB, pp. 182-207

DOMINGO, A. y SABATER, A. (2010b): "El empadronamiento de la población extranjera en los municipios catalanes de 2004 a 2008", Scriptanova, 16 (344), disponible en http://www.ub.edu/geocrit/sn/sn-344.htm [consulta: 15-1-2013] 
DOMINGO, A. y SABATER, A. (2013): “Crisis económica y emigración: la perspectiva demográfica", en Anuario de la Inmigración en España (edición 2012), Barcelona, CIDOB, pp. 62-89

ESPINOSA, P. (2013): “Con las maletas preparadas”, El País, disponible en http://ccaa. elpais.com/ccaa/2013/05/10/andalucia/1368201253_479767.html [consulta: 10-52013]

GARRIDO, L. (2004): "Para cuantificar a los extranjeros", Economistas, 99, pp. 28-37

GARRIDO, L. (2013): "Quienes se van de España y qué hacemos para que vuelvan”, El País, disponible en http://elpais.com/elpais/2013/03/27/ opinion/1364396658_219336.html [consulta: 2-4-2013]

GIL, F. (2010): “Análisis de dos propuestas metodológicas para estimar las salidas de extranjeros en España: las bajas por caducidad padronales y la renovación de las tarjetas de residencia temporales", Estadística española, 52 (174), pp. 277-309

GONZÁLEZ-FERRER, A. (2013a): "Los datos de emigración no hablan por sí solos", Eldiario.es, disponible en http://www.eldiario.es/piedrasdepapel/datos-emigracionhablan-solos_6_102599745.html, [consulta: 18-2-2013]

GONZÁLEZ-FERRER, A. (2013b): "La emigración española contada desde fuera", Eldiario.es, disponible en http://www.eldiario.es/piedrasdepapel/emigracionespanola-contada_6_125697430.html, [consulta: 25-4-2013]

GREEN, T. y WINTERS, L. A. (2010): "Economic crises and migration: Learning from the past and the present", The World Economy, 33(9), pp. 1053-1072

HATTON, T. J. (2012): The recession and international migration. Rethinking Global Economic Governance in Light of the Crisis New Perspectives on Economic Policy Foundations, London, Centre for Economic Policy Research

INTERNATIONAL LABOUR OFFICE (ILO) (2010): Policies and practices of highly skilled migration in times of the economic crisis, International Migration Papers, 99, Geneva, International Labour Office

KAHANEC, M. y ZIMMERMANN, K.F. (2011): High-Skilled Immigration Policy in Europe, Discussion Papers, Berlin, Deutsches Institut für Wirtschaftsforschung

LENOIR, R. (1993): “Objeto sociológico y problema social”, en Iniciación a la práctica sociológica, Madrid, Siglo XXI, pp. 57-103

MEARDI, G., MARTÍN, A., MOLINA, O. y VAN DEN BERG, A. (2012): "Migration and Labour Market Uncertainty in the Light of the Crisis. Segregation and Social Sustainability in Three European Countries and Two Sectors", $16^{\text {th }}$ World Congress of the International Labour and Employment Relations Association, Philadelphia, USA, Julio 2012

MARTIN, P. (2009): Recession and migration: A new era for labor migration? International Migration Review, 43 (3), pp. 671-691

MIGRATION POLICY INSTITUTE (MPI) (2008): The recession-proof race for highly skilled migrants, Washington D. C, Migration Policy Institute

OECD (2009a): The Future of International Migration to OECD Countries, OECD Publishing

OECD (2009b): "International Migration and the Economic Crisis: Understanding the Links and Shaping Policy Responses", En OECD International Migration Outlook 2009, Paris, OECD Publishing

PAPADEMETRIOU, D. G., SUMPTION, M. y A. TERRAZAS (2010): Migration and Immigrants. Two Years after the Financial Collapse: Where Do We Stand? Report for the BBC World Service, Washington D. C., Migration Policy Institute 
PLEWA, P. (2007): “The Rise and Fall of Temporary Foreign Worker Policies: Lessons for Poland", International Migration, 45(2), pp. 3-36

POULAIN, M., PERRIN, N. y SINGLETON, A. THESIM (2006): Towards Harmonised European Statistics on International Migration., Louvain, Presses Universitaires de Louvain

ROGERS, A. (2009): Recession, Vulnerable Workers and Migration, COMPAS background report, Oxford University

SABATER, A. y AJENJO, M. (2005): "Una aproximació als empadronaments atípics a Catalunya: còmput i distribució territorial d'un fenomen generalitzat", Documents d'Anàlisi Geogràfica, 46, pp. 63-89

SILVA, R. (2013): "La emigración a Alemania se dispara al nivel de hace 40 años", El País, disponible en http://economia.elpais.com/economia/2013/05/07/ actualidad/1367920585_302120.html [consulta: 5-7-2013]

SOMMERS, J. y WOOLFSON, C. (2008): 'Trajectories of Entropy and 'the Labour Question': The Political Economy of Post-communist Migration in the New Europe", Journal of Contemporary Central and Eastern Europe, 16(1), pp. 53-69

VAN DALEN, H. y HENKENS, K. (2013): "Explaining emigration intentions and behaviour in the Netherlands, 2005-10", Population Studies, 67(2), pp. 225-241 